Estudios Constitucionales, Año 16, No 1, 2018 pp. 245-280

ISSN 07180195

Centro de Estudios Constitucionales de Chile Universidad de Talca

"El derecho al agua y su protección en el contexto de la Corte Interamericana de Derechos Humanos"

Germana Aguiar Ribeiro do Nascimento

\title{
EL DERECHO AL AGUA Y SU PROTECCIÓN EN EL CONTEXTO DE LA CORTE INTERAMERICANA DE DERECHOS HUMANOS ${ }^{*-* *}$
}

\author{
THE RIGHT TO WATER AND ITS PROTECTION IN THE CONTEXT OF THE \\ INTERAMERICAN COURT OF HUMAN RigHTS
}

\author{
Germana Aguiar Ribeiro do Nascimento ${ }^{* * *}$ \\ Universidad de Valencia \\ germana.aguiar@uv.es
}

RESUMEN: El agua potable es la fuente de la vida, sin embargo, muchas personas están excluidas del acceso a la misma. Este hecho da lugar tanto a la discusión con respecto al reconocimiento formal del derecho al agua como a su aplicación efectiva. En lo que se refiere al Sistema Interamericano de Protección de los Derechos Humanos, se verifica que el derecho humano al agua no fue incorporado expresamente en los tratados o declaraciones que lo integran. Ante este contexto y teniendo en cuenta que la salvaguarda de los derechos esenciales de las personas en las Américas se produce por intermediación, sobre todo, de la actuación jurisdiccional de la Corte Interamericana de Derechos Humanos, este artículo tiene por objeto examinar, primeramente, el contenido central del derecho humano al agua, para acto seguido, verificar en qué medida la actuación contenciosa de esta Corte protege tal derecho. A partir del análisis jurisprudencial realizado, se constató que aunque este derecho no esté expresamente garantizado en los textos, la Corte Interamericana de Derechos Humanos lo reconoce como un derecho derivado de otros derechos tutelados explícitamente.

PALABRAS CLAVE: Derecho al agua, reconocimiento, Corte Interamericana.

ABSTRACT: Potable water is the source of life, however, many people are excluded from the access to it. This fact gives rise to both the discussion on the formal recognition of the right to water and its effective implementation. As far as the Inter-American System for the Protection of Human Rights is concerned, it is verified that the human right to water was not expressly incorporated by the treaties or declarations that comprise it. Given this context and taking into account that the protection of the essential rights of human beings in the Americas is produced through intermediation, above all, of the

\footnotetext{
* Artículo recibido el 26 de julio de 2017 y aprobado el 25 de abril de 2018.

** Este artículo fue realizado en el marco del proyecto Prometeo financiado por la Generalitat Valenciana, GvprometeoII2014-078 con el título "Justicia social, exigibilidad de los derechos humanos e integración" y del programa de investigación Grisolia (Ref. 2016/098), también de financiación autonómica.

*** Abogada y antropóloga brasileña. Master en Derechos Humanos en la Universidad Católica de LyonFrancia (Beca Fondation de France). Investigadora en formación en Derechos Humanos, Democracia y Justicia Internacional en la Universidad de Valencia (Beca Santiago Grisolía).
} 
jurisdictional action of the Inter-American Court of Human Rights, this article intends to examine, in a first moment, the core content of the human right to water, to then, verify to which extent the contentious action of the Court protects such right. Based on the jurisprudential analysis, it was found that even if the right to water is not expressely guaranteed in the texts, the Inter-American Court of Human Rights recognizes it as a right derived from other rights explicitly protected.

KEYWORDS: Right to water, recognition, Interamerican Court.

\section{INTRODUCCIÓN}

Es un hecho innegable que el agua potable es la fuente de la vida. Entendiendo por agua potable aquella que se destina al consumo humano, se distribuye por las redes de abastecimiento después de la recogida, el tratamiento y el almacenamiento, y que debe responder a un cierto número de características físico-químicas cualitativa y cuantitativamente y criterios microbiológicos establecidos como "normas de potabilidad1". Muchas personas todavía están excluidas del acceso a la misma. Este hecho da lugar tanto a la discusión con respecto al reconocimiento formal del derecho al agua como a su aplicación efectiva y su negación a amplios sectores de la población, esto es, a la violación del derecho.

Antes de tratar el derecho humano al agua es necesario poner de relieve que la preocupación con el agua nace en el ámbito del Derecho de Aguas y desde allí se proyecta al Derecho Internacional de los Derechos Humanos. De hecho, el Derecho de Aguas $^{2}$ corresponde a un sistema de reglas y principios que rige la manera en que debe ser desarrollada la gestión del agua y de los recursos hídricos ${ }^{3}$. El uso, el dominio, la conservación y la preservación de las aguas ilustran algunos de los aspectos que son regulados por el Derecho de Aguas. Es evidente que esta rama del derecho es crucial para la realización efectiva del derecho humano al agua. Sin embargo, el enfoque de este artículo es el acceso al agua como un derecho humano, es decir, en el ámbito del Derecho Internacional de los Derechos Humanos. De este modo, considerar el acceso al agua como un derecho humano es esencial para una vida más justa y democrática para todos, ya que muchos sufren con la ausencia de este recurso.

1 Hartemman (2013), p. 18.

2 Este tema se puede apreciar en el estudio de Movilla (2015).

3 Carli (2013), p. 56. 
En efecto, de acuerdo con el WHO/Unicef Programa para agua y saneamiento ${ }^{4}$, en 2015, 663 millones de personas aún no tenían acceso a fuentes de agua potable, ocho de cada diez de ellas viviendo en áreas rurales. Sin acceso al agua, es obvio que se vulnera el principio de la dignidad humana. En el ámbito americano, el 23 de octubre de 2015, la Comisión Interamericana de Derechos Humanos celebró una audiencia sobre "Derechos Humanos y el Agua en América", en la que se constató que del total de 580 millones de habitantes de América Latina y del Caribe, el $20 \%$ no tenía acceso a agua potable por medio de un acueducto, y menos del $30 \%$ de las aguas utilizadas recibía tratamiento, muchas veces sólo un tratamiento deficiente, resultando que 34 de cada 1.000 niños mueren cada año en esta región por enfermedades asociadas al agua 5 .

Además, en la audiencia se destacó que la situación de escasez de abastecimiento de agua se habría agravado dada la creciente presión por los recursos naturales para el desarrollo de actividades extractivas, entre las que se destacan: la construcción de represas y la explotación minera. Tales actividades han ocasionado distintas violaciones de derechos humanos, como por ejemplo, el desplazamiento forzado de personas y comunidades, violaciones sistemáticas al derecho a la consulta previa de los pueblos indígenas y tribales, y a la participación efectiva en materia ambiental de las comunidades campesinas ${ }^{6}$. De esta manera, la consideración del acceso al agua como un derecho humano traduce una necesidad de un derecho legítimo ${ }^{7}$.

A pesar de este escenario, el derecho al agua no fue incorporado expresamente en los tratados o declaraciones que integran el Sistema Interamericano de Protección de los Derechos Humanos. Ante este contexto y teniendo en cuenta que la salvaguarda de los derechos esenciales de los seres humanos en las Américas se produce por intermediación, sobre todo, de la actuación jurisdiccional de la Corte Interamericana de Derechos Humanos, se observa que surge cada vez más, en el marco del Sistema Interamericano, un gran número de demandas que revelan la vulnerabilidad de los derechos económicos, sociales y culturales, por ejemplo, del derecho al agua.

\footnotetext{
4 Who and Unicef (2015), p. 5.

5 Comisión Interamericana de Derechos Humanos (2015), p. 481.

6 Comisión Interamericana de Derechos Humanos (2015), p. 482.

7 WinKLer (2012), p. 228.
} 
En este sentido, este artículo tiene por objeto examinar, en primer lugar, el contenido central del derecho humano al agua. De hecho, una de las tesis que sostiene que los derechos sociales, económicos y culturales son inferiores, no son justiciables o lo son en medida reducida, se apoya en el hecho de que el objeto de la mayoría de los derechos fundamentales sociales es impreciso. Así, es crucial, preliminarmente, definir el contenido del derecho al agua. Acto seguido, se verificará en qué medida la actuación contenciosa de la Corte Interamericana de Derechos Humanos protege este derecho, atendiendo al trato que el derecho ha recibido en el contexto de dicha Corte. Se trata de un estudio de abordaje cualitativo que hace uso de la investigación bibliográfica y documental como principales procedimientos técnicos, habida cuenta que se respalda en el uso de fuentes teóricas, de legislación y jurisprudencias de la Corte. De esta forma, inicialmente, se examinará, el derecho al agua como derecho humano y su contenido, y luego el trato conferido por la Corte Interamericana al referido derecho, observándose el alcance de su protección en la esfera judicial.

\section{El DERECHO HUMANO AL AGUA: ALCANCE Y CONTENIDO}

Actualmente el derecho humano al agua se ha convertido en un derecho reconocido sólidamente en el ámbito del derecho internacional, sobre todo dentro del sistema de protección de los derechos humanos de Naciones Unidas. De hecho, como señala Leb, esto puede ser visto como una respuesta de los Estados "a la circulación en los medios de comunicación de un sinnúmero de imágenes de personas que mueren de hambre, de sed y de las enfermedades de cólera y de otras transmitidas por el agua en regiones afectadas por catástrofes naturales u otras calamidades 8 ". Por consiguiente, diversas normas jurídicas fueron elaboradas para mitigar el impacto de tales crisis ${ }^{9}$. La importancia del derecho al agua es confirmada por su reconocimiento como norma de derecho humano en varios tratados internacionales, declaraciones y otros instrumentos ${ }^{10}$.

De este modo, a lo largo de las últimas décadas, han ido apareciendo una serie de instrumentos con vistas a la protección del derecho al agua, tales como los textos y conferencias internacionales de derechos humanos y de protección del

8 LeB (2012), p. 341.

9 LeB (2012), p. 341.

10 SINGH (2013), p. 943. 
medio ambiente ${ }^{11}$. Sin embargo, fue sólo a partir del 28 de julio de 2010, después de muchas negociaciones de la comunidad internacional, cuando la Asamblea General de las Naciones Unidas adoptó la Resolución 64/292 reconociendo expresamente el agua limpia y segura y el saneamiento como derechos básicos para el pleno disfrute de la vida y de todos los demás derechos humanos ${ }^{12}$. La Resolución del Consejo de Derechos Humanos 15/913, titulada "Los derechos humanos y el acceso al agua potable y el saneamiento", reafirmó tal derecho también en 2010. En efecto, los textos anteriores no preveían este derecho de forma autónoma, habría que recurrir a la interpretación para defenderlo ${ }^{14}$. Es el caso de la Declaración Universal de los Derechos Humanos de 1948 y de los Pactos de $1966^{15}$. En el ámbito interamericano, se verá en la sección siguiente que también se sigue esta tendencia.

$\mathrm{Al}$ igual que el resto de los derechos económicos, sociales y culturales, el derecho humano al agua no fue tratado como prioridad por la comunidad internacional y aunque ahora esté finalmente reconocido de forma autónoma por las Naciones Unidas, hay dudas en torno a su alcance ${ }^{16}$. Por consiguiente, es crucial determinar el contenido central de este derecho, para que los Estados no se eximan de sus responsabilidades.

Así, McGraw ${ }^{17}$ destaca que la definición formal del derecho al agua es necesaria porque sin ella hay un riesgo para la paz internacional, para el diálogo de los derechos humanos y para los individuos, que no tendrían los mecanismos necesarios

\footnotetext{
11 En el ámbito internacional pueden destacarse la Conferencia de las Naciones Unidas sobre el Agua de 1977, la Conferencia de las Naciones Unidas sobre el Medio Ambiente y el Desarrollo de 1992 y su Programa 21 o la Conferencia de las Naciones Unidas sobre los Asentamientos Humanos en 1996 y su programa Hábitat.

12 Tsanga and Gremmel (2013), pp. 56-64.

13 Human Rights Council (2010).

14 Serrano (2014), p. 12.

15 El derecho humano al agua puede ser inferido del artículo 25 de la Declaración Universal de los Derechos Humanos de 1948 que afirma que "Toda persona tiene derecho a un nivel de vida adecuado que le asegure, así como a su familia, la salud y el bienestar, y en especial la alimentación, el vestido, la vivienda, la asistencia médica $y$ los servicios sociales necesarios (...)". En el mismo sentido, el Pacto Internacional relativo a los Derechos Económicos, Sociales y Culturales de 1966, que garantiza el derecho de toda persona a un nivel de vida adecuado, a la salud y la alimentación en los artículos 11 y 12 . El artículo $6^{\circ}$ del Pacto Internacional de Derechos Civiles y Políticos de 1966, que protege el derecho a la vida, también garantiza en alguna medida el derecho al agua.

16 Movilla (2012), p. 3.

17 McGraw (2010), p. 45.
} 
para proteger este derecho. Con vistas a clarificar el fundamento jurídico del derecho al agua, el Comité de Derechos Económicos, Sociales y Culturales (Comité DESC), órgano de supervisión del Pacto Internacional de Derechos Económicos, Sociales y Culturales, elaboró la Observación General No $15^{18}$. A esos efectos, en su párrafo segundo, la Observación afirma que "el derecho humano al agua es el derecho de todos a disponer de agua suficiente, salubre, aceptable, accesible y asequible para el uso personal y doméstico. Un abastecimiento adecuado de agua salubre es necesario para evitar la muerte por deshidratación, para reducir el riesgo de las enfermedades relacionadas con el agua y para satisfacer las necesidades de consumo y cocina y las necesidades de higiene personal y doméstica".

Como afirma Cahill ${ }^{19}$, la definición parece ser obvia pero necesita un análisis para comprender lo que significa en la práctica. De manera similar, Ziganshina ${ }^{20}$ afirma que la Observación General No 15 determina las bases del derecho al agua pero es preciso desarrollar estas bases para reforzar el objetivo y la protección de este derecho a través del establecimiento de una legislación de carácter obligatorio en los niveles nacional e internacional. Al Jayyousi ${ }^{21}$ destaca que afirmar el derecho humano al agua es tener como prioridad las necesidades humanas relativas al uso del agua. De ahí que es importante estudiar los elementos clave de este derecho, enunciados por la Observación General No 15: disponibilidad, calidad y accesibilidad.

El Comité DESC establece que el agua disponible para cada persona debe ser continua y suficiente para los usos personales y domésticos. Se trata del principio de disponibilidad, establecido en el párrafo 12 (a) "El abastecimiento de agua de cada persona debe ser continuo y suficiente para los usos personales y domésticos. Esos usos comprenden normalmente el consumo, el saneamiento, la colada, la preparación de alimentos y la higiene personal y doméstica. La cantidad de agua disponible para cada persona debería corresponder a las directrices de la Organización Mundial de la Salud (OMS). También es posible que algunos individuos y grupos necesiten recursos de agua adicionales en razón de la salud, el clima y las condiciones de trabajo".

18 Comité Desc (2002).

19 Cahill (2005), p. 392.

20 Ziganshina (2008), p. 116.

${ }^{21}$ AL JaYyousi (2007), p. 330. 
Saura ${ }^{22}$ destaca que "si continuo significa "permanente» y podría asociarse normalmente a «agua corriente» sin interrupción, suficiente puede significar distintas cosas en función de las circunstancias geográficas, climáticas, económicas y culturales de cada país". En el mismo sentido, Gleick ${ }^{23}$ alerta que la disponibilidad del agua es limitada, por ejemplo, por factores económicos y políticos y por cuestiones relacionadas al ecosistema. Por consiguiente, el derecho al agua no significa, según este autor, un derecho a una cantidad de agua ilimitada. De forma similar, el relator El Hadji Guissé24 afirmaba en 2005 que "los Estados deberían aplicar medidas para evitar un consumo excesivo y favorecer un aprovechamiento eficaz del agua, por ejemplo mediante la educación, la difusión de técnicas apropiadas de conservación y, en caso necesario, la limitación del uso más allá de un consumo razonable, incluso mediante un aumento de las tarifas".

Por esta razón, se ha discutido acerca de la cantidad mínima de agua que debe ser garantizada para cada individuo. Algunos instrumentos internacionales especializados han establecido criterios para este contenido mínimo necesario para los usos personales y domésticos. Aunque no haya una definición pacífica de lo que son los usos personales y domésticos, ellos incluyen, sin lugar a dudas, como afirma Sánchez ${ }^{25}$ : “a) agua para beber (hidratación); b) destinada a la preparación, elaboración o conservación de alimentos; c) para la higiene personal y doméstica (limpieza del cuerpo, del hogar, evacuación de aguas sucias, etc.); d) y, en su caso, como agua de riego para la obtención de alimentos agrícolas o de consumo animal, cuando esta disponibilidad guarda para el individuo una relación directa con su derecho a la alimentación (en el caso del autoabastecimiento de comunidades rurales)".

Howard y Bartram ${ }^{26}$ destacaban ya en 2003 que aunque hubiese muchos debates acerca de las directrices para determinar la cantidad mínima de agua necesaria para los usos domésticos y personales, aun no teníamos una norma universal aceptada. Para ilustrar esa realidad, estos autores enfatizaban que uno de los Objetivos de Desarrollo del Milenio era reducir a la mitad, para 2015, la proporción de personas sin acceso sostenible al agua potable, pero que este objetivo

22 SAURA (2012), p. 159.

23 GLEICK, (2007), p. 4.

24 El Hadji (2005).

25 SÁNCHEZ (2008), p. 15.

26 HoWARD AND BARTRAM (2003). 
no determinaba la cantidad de agua necesaria para cada persona. La realidad sigue siendo la misma, no hay una norma universal para definir la cantidad mínima de agua. Para Mitre ${ }^{27}$, el estado de disponibilidad entraña un criterio cuantitativo, es decir, la disponibilidad de agua debe estar basada en una cantidad mínima de agua para cada persona.

El WHO/Unicef ${ }^{28}$ define el acceso básico para las necesidades de usos domésticos y personales de agua que viene siendo, en términos generales, la disponibilidad de al menos 20 litros por persona y día desde una fuente a un kilómetro de la vivienda del usuario. Esta cantidad correspondería al mínimo social básico universal, siendo 7,5 litros de agua los necesarios para el consumo de boca o alimentación.

Es importante clarificar que esta cantidad no es la cantidad recomendable, ya que con solamente 20 litros de agua la higiene puede estar comprometida ${ }^{29}$. De hecho, si hay recursos hídricos suficientes, un gobierno debería asegurar en torno a 100 litros por persona y día ${ }^{30}$, siendo esta la cantidad que la Organización Mundial de la Salud considera óptima.

En el proyecto de directrices para la realización del derecho al agua potable y al saneamiento, el relator El Hadji Guissé31, destacó que "Los Estados deberían velar por que haya agua salubre en cantidad suficiente para todas las personas, adoptando y aplicando estrategias y programas de gestión integrada de los recursos hídricos y planes eficaces de aprovechamiento del agua, luchando contra la disminución de los recursos hídricos a causa de las extracciones, los desvíos o la construcción de embalses sin criterios de sostenibilidad, reduciendo las pérdidas en la distribución de agua y previendo mecanismos para hacer frente a situaciones de emergencia”. El proyecto de directrices enfatiza así que el principio de disponibilidad requiere obligaciones de la parte de los Estados.

Además, la experta independiente Catarina de Albuquerque ${ }^{32}$ demuestra que a la hora de planificar el acceso al agua es necesario tener en cuenta cuestiones de orden ambiental, es decir "el crecimiento de la población humana y las acti-

\footnotetext{
27 Mitre (2012), p. 184.

28 Who and Unicef (2000), p. 1.

29 World Health Organization (2003), p. 13.

30 De Luis Romero et al. (2013), p. 226.

31 El HadjI (2005).

32 De Albuquerque (2012), p. 129.
} 
vidades contaminantes específicas de los seres humanos están causando daños al medio ambiente tanto en las zonas urbanas como en las rurales. A menudo, los recursos hídricos son los más afectados por ello. Además, el cambio climático está afectando a la disponibilidad de recursos de agua potable. A la hora de planificar la mejora del acceso a los servicios de abastecimiento de agua y de saneamiento es preciso tener en cuenta los dos problemas mencionados, a fin de garantizar que las generaciones futuras continúen teniendo acceso a cantidades suficientes de agua potable y que se adopten las medidas de mitigación necesarias para gestionar el agua en tiempos de estrés hídrico, ya sea como consecuencia de inundaciones o de sequías".

El elemento disponibilidad es así directamente dependiente de la salud de los recursos hídricos. De hecho, el objetivo número 6 de los Objetivos de Desarrollo Sostenible de la Resolución "Transformar nuestro mundo: la Agenda 2030 para el Desarrollo Sostenible”, adoptada por las Naciones Unidas en 2015, confirma esta relación de dependencia. Este objetivo afirma la necesidad de garantizar la disponibilidad y la gestión sostenible del agua y el saneamiento para todos.

Los países tienen la obligación no solo de poner a disposición agua para sus poblaciones, sino además esta agua debe ser agua de calidad. Los nuevos ODM deberían, según la relatora, tener en cuenta la cuestión de la calidad. Es decir, el agua no debe tener un olor, un color, pero debe tener un sabor aceptable para cada uso. La Organización Mundial de la Salud ${ }^{33}$ determina que el agua de consumo inocua (agua potable) no ocasiona ningún riesgo significativo para la salud cuando se consume durante toda una vida, teniendo en cuenta las diferentes vulnerabilidades que pueden presentar las personas en las distintas etapas de su vida.

Sin embargo, Sánchez ${ }^{34}$ destaca que la potabilidad del agua no debe ser necesariamente la misma y puede ajustarse a cada uno de sus usos esenciales. Para demostrar eso, el autor afirma que el agua destinada a la higiene personal puede tener unos índices de calidad menores que la que tiene como fin el consumo de las personas. $\operatorname{Tur}^{35}$ se suma a esta idea añadiendo que el criterio de calidad se encuentra vinculado con el de aceptabilidad. De hecho, en la Observación General No 12 relativa al derecho a la alimentación, el Comité de Derechos Económicos, Sociales y Culturales, incluye la aceptabilidad como un elemento jurídico de este

33 Oms (2008), p. 11.

34 SANChez (2008), p. 15.

35 Serrano (2014), p. 137. 
derecho. Esta autora destaca la importancia de este criterio porque está relacionado con una dimensión cultural, de la que aparentemente carece el derecho al agua, ya que no aparece en la Observación General No 15. De hecho, todas las instalaciones y servicios de agua deben ser adecuados y sensibles a las necesidades culturales, de género, de ciclo vital y de privacidad de las personas. Para ilustrar esta preocupación, la autora cita el caso de los pueblos indígenas, afirmando que "la puesta en práctica del derecho al agua y al saneamiento debe ser sensible a las cuestiones culturales y/o tradicionales ancestrales de cada contexto en el que se aplica, y debe tener en cuenta, otros derechos como por ejemplo, el de los grupos indígenas".

El elemento de calidad también está relacionado directamente con las cuestiones del medio ambiente. De este modo, uno de los Objetivos de Desarrollo Sostenible establecido en el párrafo 6.4 es de garantizar la disponibilidad del agua mejorando "la calidad del agua reduciendo la contaminación, eliminando el vertimiento y minimizando la emisión de productos químicos y materiales peligrosos, reduciendo a la mitad el porcentaje de aguas residuales sin tratar y aumentando considerablemente el reciclado y la reutilización sin riesgos a nivel mundial”. El agua debe así ser disponible, de calidad y accesible.

La Observación General No 15 determina que "el agua y las instalaciones y servicios de agua deben ser accesibles para todos, sin discriminación alguna, dentro de la jurisdicción del Estado Parte". La accesibilidad, de acuerdo con la Observación, presenta cuatro dimensiones superpuestas: la accesibilidad física, la accesibilidad económica, la no-discriminación y el acceso a la información.

La Organización Mundial de la Salud ${ }^{36}$ afirmaba en 2003 que la accesibilidad física significaba que todos deberían tener acceso a los servicios de agua de una forma segura y fácil. Es decir, si el agua tiene que ser tomada en fuentes muy lejanas, la salud de las personas está en riesgo. De hecho, la Organización destaca que la salud de las mujeres y la de los niños es la principal afectada cuando las fuentes de agua están lejanas, ya que son ellos los que tienen que ir a por el agua. Ella enfatiza que las mujeres pueden ser atacadas sexualmente y también sufrir problemas en la espalda debido a las cantidades de agua que tienen que cargar. Los niños vienen siendo víctimas de los mismos problemas.

La Organización estableció una tipología para evaluar si la accesibilidad física está siendo respetada. Por lo tanto, si la persona tiene que caminar más de treinta

36 World Health Organization (2003), p. 15. 
minutos para recoger el agua, es decir, más de un kilómetro, se puede considerar que ella no tiene acceso al agua y normalmente va a recoger un pequeño volumen de la misma, menor que el necesario para la higiene personal y para el consumo doméstico. Estas necesidades estarían así comprometidas. Si la persona tiene que caminar cerca de 30 minutos o un kilómetro, se considera que ella tiene un acceso básico al agua. Sin embargo, tendrá solamente agua para el consumo y su higiene podrá ser comprometida. El acceso intermediario al agua puede ser verificado cuando la persona tiene acceso a un grifo en su terreno y el acceso óptimo cuando la persona tiene acceso a varios grifos en su casa.

Por otro lado, la accesibilidad económica es definida por Catarina de Albuquerque $^{37}$ de la siguiente manera: "los servicios de agua y saneamiento deben ser asequibles para todas las personas, y en ningún caso el pago de los mismos debe limitarles poder disfrutar de otros derechos humanos, como la vivienda, alimentación o salud. Esto puede garantizarse, por ejemplo, mediante una estructura tarifaria eficaz que asegure que los hogares más pobres paguen una tarifa inferior por disponer de una cantidad básica de agua". El folleto informativo de las $\mathrm{Na}$ ciones Unidas No 35 sobre el derecho al agua ${ }^{38}$ afirma que de por sí, el marco de los derechos humanos no establece el derecho a un suministro de agua gratuito. Sin embargo, añade que, en determinadas circunstancias, el acceso al agua potable y servicios de saneamiento puede tener que ser gratuito si la persona o la familia no pueden adquirirlo, destacando que es una obligación básica del Estado velar por que se satisfagan por lo menos los niveles esenciales mínimos del derecho, lo que comprende el acceso a la cantidad mínima indispensable de agua.

En lo que se refiere al principio de no discriminación, es necesario enfatizar que tal principio no es específico al derecho al agua pero es un principio básico del sistema de protección de los derechos humanos presente en la mayoría de los instrumentos legales de este sistema ${ }^{39}$. Así, es el caso de la Declaración Universal de los Derechos Humanos, de los Pactos de 1966 y de la Declaración de los Derechos del Niño de 1989. Los grupos vulnerables son los que más sufren con la violación de sus derechos humanos, como los pueblos indígenas, las mujeres, los niños, las personas sin hogar, las personas mayores, los presos, los refugiados, las personas con discapacidad, etc. Los casos que serán analizados en la última

37 De Albuquerque (2012), p. 129.

38 Naciones Unidas (2010), p. 12.

39 Taylon and Nylund (2013), p. 46. 
sesión de este artículo corroboran esta afirmación. Para evitar que estos grupos sean víctimas de la falta de acceso al agua, el párrafo 16 de la Observación General No 15 afirma que "aunque el derecho al agua potable es aplicable a todos, los Estados Partes deben prestar especial atención a las personas y grupos de personas que tradicionalmente han tenido dificultades para ejercer este derecho, en particular las mujeres, los niños, los grupos minoritarios, los pueblos indígenas, los refugiados, los solicitantes de asilo, los desplazados internos, los trabajadores migrantes, los presos y los detenidos".

El último principio es el de acceso a la información, como afirma Catarina de Albuquerque ${ }^{40}$ la participación y el acceso a la información han sido durante mucho tiempo aspectos fundamentales de las buenas prácticas en el ámbito del desarrollo, puesto que han contribuido a garantizar la aceptabilidad, la asequibilidad y la sostenibilidad de los servicios de agua y saneamiento. En este sentido, el párrafo 37 de la Observación General No 15 afirma que para la implementación del derecho al agua es necesario "adoptar y aplicar una estrategia y un plan de acción nacionales sobre el agua para toda la población; la estrategia y el plan de acción deberán ser elaborados y periódicamente revisados en base a un proceso participativo y transparente; deberán prever métodos, como el establecimiento de indicadores y niveles de referencia que permitan seguir de cerca los progresos realizados; el proceso mediante el cual se conciban la estrategia y el plan de acción, así como el contenido de ambos, deberán prestar especial atención a todos los grupos vulnerables o marginados".

Se percibe así que el contenido del derecho al agua está definido expresamente en el ámbito internacional. De esta forma, los Estados no pueden más sostener que la ausencia de un objeto preciso impide la realización y judicialidad de este derecho. En la próxima sección se analizará en qué medida el sistema interamericano protege este derecho en sus textos, ya que las poblaciones de los países parte de este sistema están entre las que más sufren con la falta de acceso a este recurso. De hecho, los casos de la Corte Interamericana que serán estudiados en la última sección ilustran esta situación.

\section{EL DERECHO INTERAMERICANO: APORTES Y LIMITACIONES AL DERECHO HUMANO AL AGUA}

En el ámbito interamericano hay una Organización con significante impacto en los derechos humanos: la Organización de los Estados Americanos. De hecho,

40 De Albuquerque (2012), p. 37. 
la carta que da origen a esta Organización, afirma los "derechos fundamentales de la persona humana" como uno de sus principios fundadores. Efectivamente, el pleno respeto de los derechos humanos aparece en varias sesiones de la Carta. De acuerdo con ese instrumento, "el sentido genuino de la solidaridad americana y de buena vecindad no puede ser otro que el de consolidar en este continente dentro del marco de las instituciones democráticas, un régimen de libertad individual y de justicia social, fundado con respeto a los derechos esenciales del hombre".

A pesar de no referirse al derecho al agua, se observa que en el artículo 34 de la Carta se prevén los objetivos básicos del desarrollo integral: la igualdad de oportunidades, la eliminación de la pobreza y la distribución equitativa de la riqueza y la renta, así como la plena participación de sus pueblos en las decisiones relativas a su propio desarrollo, entre otros. Para alcanzarlos, los Estados deben dedicar sus mayores esfuerzos a la consecución de las siguientes metas básicas: alimentación adecuada para todos, especialmente a través de la aceleración de los esfuerzos nacionales para aumentar la producción y disponibilidad de alimentos y condiciones urbanas que proporcionen oportunidades de vida sana, productiva y digna.

Según el Informe ya mencionado de la Comisión Interamericana de Derechos Humanos $^{41}$, la consecución de dichas metas depende irreductiblemente del acceso al agua apta para el consumo humano. Este acceso debe ser garantizado en condiciones de igualdad real para la satisfacción de todos los derechos humanos. Se trata del punto de partida para un desarrollo integral. Además, la Resolución AG/RES. No 2.349 (XXXVII-O/07) "El agua, la salud, y los derechos humanos", de la Asamblea General de la Organización de los Estados Americanos, aprobada en la cuarta sesión plenaria, celebrada el 5 de junio de 2007, resalta que incumbe a los gobiernos la función primera de promover un mayor acceso al agua potable, afirmando que "el agua es esencial para la vida y la salud de todos los seres humanos y que el acceso al agua potable y la higiene básica son indispensables para vivir una vida con dignidad". Añade también la necesidad de "respetar el uso ancestral del agua por parte de las comunidades urbanas, rurales y pueblos indígenas, en el marco de sus usos y costumbres".

Strakos ${ }^{42}$ destaca que este documento ha sido señalado por algunos, por ejemplo Hohenwarter, como un retroceso en el reconocimiento del agua como derecho humano, teniendo en cuenta la omisión de una definición expresa del

41 Comisión Interamericana de Derechos Humanos (2015), p. 487.

42 Strakos (2016), p. 150. 
acceso al agua como derecho humano, lo que había sido sugerido por la delegación de Bolivia en el contexto de las negociaciones. Así, la falta de reconocimiento del derecho al agua como un derecho humano debilitaría la capacidad de aplicación de este derecho, su reconocimiento podría hacer más eficaz su efectividad y permitir un desarrollo más rápido de la jurisprudencia, constituyendo así, un mecanismo eficaz para el cambio en el nivel nacional ${ }^{43}$.

La Carta Social de las Américas, aprobada por la Asamblea General de la Organización de los Estados Americanos, el 4 de junio de 2012, tampoco se refiere al acceso al agua como un derecho humano. Efectivamente, se dispone expresamente en su artículo 20 que: "Los Estados miembros reconocen que el agua es fundamental para la vida y básica para el desarrollo socioeconómico y la sostenibilidad ambiental, y que el acceso no discriminatorio de la población al agua potable y los servicios de saneamiento, en el marco de las legislaciones y políticas nacionales, contribuye al objetivo de combatir la pobreza. Los Estados miembros, sobre la base de sus respectivas realidades nacionales, se comprometen a seguir trabajando para asegurar el acceso al agua potable y a los servicios de saneamiento para las generaciones presentes y futuras".

La primera resolución en el ámbito interamericano que menciona un derecho humano al agua es la Resolución AG/RES. No 2.760 (XLII-O/12) "El derecho humano al agua potable y al saneamiento", de la Asamblea General de la Organización de los Estados Americanos. Esta resolución fue aprobada en la cuarta sesión plenaria, celebrada el 5 de junio de 2012, y afirma que "la importancia de que cada Estado siga trabajando para asegurar a los individuos sujetos a su jurisdicción, de acuerdo con su legislación nacional, el acceso no discriminatorio al agua potable y al saneamiento como componentes integrales de la realización de todos los derechos humanos". Aunque sea un progreso, en los textos clave de protección de los derechos humanos de este sistema, no se habla de derecho humano al agua, lo que demuestra la necesidad de avanzar en este sentido.

\subsection{La previsión del derecho humano al agua en el} Sistema Interamericano de Protección de los Derechos Humanos

El sistema interamericano de protección de los derechos humanos se inició formalmente con la aprobación de la Declaración Americana de Derechos y De-

43 STeiner (2004), p. 21. 
beres del Hombre en la Novena Conferencia Internacional Americana celebrada en Bogotá en 1948. Según De Oliveira ${ }^{44}$, esta Declaración formó la base normativa de protección en el Sistema Interamericano y sigue siendo el instrumento de expresión regional en esta materia, principalmente para los Estados que no han firmado la Convención Americana. De hecho, en noviembre de 1969 se celebró la Conferencia Especializada Interamericana sobre Derechos Humanos en San José, Costa Rica, donde se redactó la Convención Americana sobre Derechos Humanos, que protege, esencialmente, derechos civiles y políticos y que entró en vigor el 18 de julio de 1978. Así como los textos mencionados en el ámbito internacional, la prioridad fue dada a los derechos civiles y políticos.

En lo que se refiere al derecho al agua, se constata que la Declaración Americana no reconoce expresamente dicho derecho. Sin embargo, ella garantiza, en el artículo I, el derecho a la integridad personal y, en el artículo XI, el derecho a la salud, incluso, afirmando su protección por medio de medidas sanitarias y sociales relativas a la alimentación, ropa, vivienda y cuidados médicos correspondientes al nivel permitido por los recursos públicos y los de la colectividad ${ }^{45}$.

En el mismo sentido, la Convención Americana sobre Derechos Humanos tampoco prevé el derecho al agua, pero protege el derecho a la vida, en su artículo $4^{\circ}$; el derecho a la integridad personal, en su artículo $5^{\circ}$ y reconoce en su artículo 1.1 la obligación de los Estados Partes de respetar los derechos y libertades en ella reconocidos y garantizar su libre y pleno ejercicio a toda persona que esté sujeta a su jurisdicción, sin discriminación alguna. Obliga aun a los Estados a adoptar, de acuerdo con sus normas constitucionales y con las disposiciones de la Convención, las medidas legislativas o de otra naturaleza que sean necesarias para hacer efectivos tales derechos y libertades, en su artículo $2^{\circ}$.

El Protocolo de San Salvador ${ }^{46}$ tampoco hace mención expresa al derecho al agua. Sin embargo, en su artículo 11.1 prevé que toda persona tiene derecho a vivir en un medio ambiente sano y a contar con los servicios públicos básicos. Así, el agua potable es uno de los servicios esenciales para la subsistencia de las personas y el derecho a su suministro estaría implícito en este artículo. Para Salmón G. ${ }^{47}$, “el derecho a un medio ambiente adecuado se encuentra relacionado con el derecho

\footnotetext{
44 De Oliveira (2015), p. 974.

45 Declaración Americana de los Derechos y Deberes del Hombre (1948).

46 Protocolo Adicional a la Convención Americana sobre Derechos Humanos (1988).

47 SALMÓN (2012), p. 259.
} 
al agua y a la vida digna especialmente en países como los latinoamericanos, donde las actividades extractivas y la protección del medio ambiente mantienen relaciones muy tensas". Por lo tanto, es posible afirmar que el derecho al agua se deduce de los aludidos derechos y no es reconocido expresamente como un derecho autónomo.

Aunque el no reconocimiento de este derecho sea una limitación, es posible defenderlo, como lo hace Buob Concha ${ }^{48}$, al afirmar que el hecho de no haber reconocimiento expreso del derecho humano al agua en la Convención Americana de Derechos Humanos, principal instrumento interamericano de protección de los derechos humanos "en sí mismo no impide prima facie su reconocimiento y tutela jurisprudencial". Así, a través de la actuación de los mecanismos de protección del sistema interamericano, que serán analizados en la sesión siguiente, se ha entendido por el reconocimiento del mencionado derecho como un derecho derivado de los derechos expresamente protegidos, lo que será observado en la última parte de este trabajo.

\subsection{Los mecanismos de protección del Sistema Interamericano}

Con el fin de salvaguardar los derechos esenciales del hombre en las Américas, la Convención instrumentalizó su actuación a partir de dos órganos competentes para conocer las violaciones de los derechos humanos: la Comisión Interamericana de Derechos Humanos y la Corte Interamericana de Derechos Humanos. El sistema interamericano está dotado así de una estructura atípica, bicéfala, a través de la cual el control del respeto de los derechos humanos por los Estados Partes es ejercido por una Comisión y una Corte ${ }^{49}$.

La Comisión Interamericana de Derechos Humanos fue creada en 1959 en Santiago de Chile durante la V Reunión de Consulta de los Ministros de Relaciones Exteriores de la OEA, a partir de la Resolución VIII. Ella inició sus operaciones en 1960, cuando el Consejo de la OEA aprobó su Estatuto que afirmaba que su función sería promover los derechos establecidos tanto en la Carta de la OEA, como en la Declaración Americana de los Derechos y Deberes del Hombre. En este contexto, Farias ${ }^{50}$ destaca dos aspectos: que la Comisión Interamericana existía

48 Buob Concha (2012), p. 140.

49 Hennebel y Tigroudja (2009), p. 76.

50 Farias (2013), p. 5. 
anteriormente al Pacto de San José de Costa Rica y que también ejerce funciones ante la Organización de los Estados Americanos.

De acuerdo con la Carta de la OEA, la Comisión Interamericana es, además de órgano de la OEA, también órgano de la Convención Americana de Derechos Humanos, por lo que tiene funciones ambivalentes. De ese modo, se observa que los Estados que no ratificaron esta Convención no quedan desvinculados de sus obligaciones asumidas en los términos de la Carta de la OEA y de la Declaración Americana de los Derechos y Deberes del Hombre, de 1948. Ella tiene como principal función la de promover la defensa de los derechos humanos, además de las dispuestas en el artículo 41 de la Convención Americana.

La Corte, por su parte, no pudo ser establecida y organizada hasta que la Convención Americana entró en vigor, en 1978. De acuerdo con el artículo $1^{\circ}$ de su Estatuto, la Corte Interamericana de Derechos Humanos es una institución judicial autónoma cuyo objetivo es la Aplicación e interpretación de la Convención Americana sobre Derechos Humanos. Ella debe ejercer sus funciones de conformidad con las disposiciones de dicho Convenio y del Estatuto. Como subraya Ramos, en cuanto a "Segundo órgano de la Convención Americana, la Corte es una institución judicial autónoma, no siendo órgano de la OEA, sino de la Convención Americana de Derechos Humanos ${ }^{51 " . ~}$

Respecto de las funciones, el artículo $2^{\circ}$ de dicho Estatuto prevé que la Corte ejerza una función jurisdiccional, regida por las disposiciones de los artículos 61, 62 y 63 de la Convención, y consultiva, regida por las disposiciones del artículo 64 de la Convención. En relación con la competencia consultiva, se puede afirmar que se trata del medio por el cual la Corte responde a consultas hechas por Estados miembros de la OEA u órganos de los mismos en cuanto a la interpretación de las disposiciones de la Convención, así como de las disposiciones de tratados concernientes a la protección de los derechos humanos en los Estados Americanos.

Por lo que se refiere a la competencia contenciosa, de carácter jurisdiccional, la Corte examina y juzga casos concretos, cuando se alega que uno de los Estados Partes en la Convención violó alguno de sus preceptos. Por lo tanto, tiene jurisdicción sobre todos los casos relativos a la interpretación y aplicación de las disposiciones del Convenio que le sean sometidos, siempre que los Estados Partes en el caso hayan reconocido o reconozcan dicha competencia.

51 Ramos (2002), p. 228. 
De este modo, la Corte Interamericana se dirige contra los Estados Miembros que hayan ratificado la Convención Americana y que hayan aceptado, de forma explícita, su competencia contenciosa. El ejercicio de esta competencia en cuanto al reconocimiento y tutela del derecho al agua será, así, objeto de la sección siguiente.

\section{EXAmen JuRisprudencial en El Ámbito de la Corte InTERAMERICANA}

En el ejercicio de la competencia contenciosa de la Corte Interamericana de Derechos Humanos, es posible observar que no hay referencia expresa al derecho humano al agua, por no haber existido, en el marco del sistema interamericano, el reconocimiento explícito de ese derecho, como ya se ha examinado. Sin embargo, a partir de la jurisprudencia de la Corte, se constata que ésta hace alusión al acceso al agua. De hecho, cuando la Corte desarrolla el contenido de otros derechos humanos expresamente reconocidos en los instrumentos interamericanos, ella se refiere al acceso al agua por entender que su satisfacción guarda relación con tales derechos.

De acuerdo con el Informe de la Comisión Interamericana de Derechos Humanos del año 2015, se verifica, en el contexto de la Corte, el desarrollo progresivo de jurisprudencia que aborda el acceso al agua, habiendo importantes decisiones que destacan la obligación del Estado de garantizar el acceso al agua sin discriminación, a saber: las decisiones relativas a los detenidos y las decisiones relativas a las comunidades indígenas. Para Guerra ${ }^{52}$, estas decisiones se basan a partir de la interpretación evolutiva y teleológica de reglas convencionales junto con el entorno sociológico en que se produce la violación de derecho, por lo que sostiene que el principal valor de esas sentencias es que su naturaleza interpretativa favorece la delimitación de conceptos y de los derechos. Tales decisiones serán analizadas a continuación. Es interesante destacar que aunque representen progresos, aún hay mucho trabajo por hacer. De hecho, es primordial reconocer el acceso al agua como un derecho humano, ya que ayudaría tanto a centrar la atención en el estado de la gestión del agua y en establecer prioridades en las políticas como a garantizar un universal acceso a un agua limpia y de calidad.

52 Mitre (2012), p. 243. 


\subsection{Las decisiones referentes a los detenidos: el acceso al agua como derecho derivado}

Algunas decisiones de la Corte Interamericana que mencionan el derecho al agua son las que se refieren a los detenidos. Efectivamente, como ya mencionado, los detenidos hacen parte de las poblaciones más vulnerables, que sufren con la violación de sus derechos. Ilustra esta situación un caso contra la República de Honduras. Efectivamente, el 7 de julio de 2003, la Comisión Interamericana de Derechos Humanos presentó ante la Corte una demanda contra la República de Honduras, bajo la alegación de que el señor Alfredo López Álvarez fue privado de su libertad personal a partir del 27 de abril de 1997, fecha en la que fue detenido por posesión y tráfico ilícito de estupefacientes, habiendo permanecido detenido hasta el 26 de agosto de 2003, a pesar de que desde el 13 de enero de 2003, el Tribunal de Primera Instancia dictó sentencia absolviéndolo.

En lo que se refiere al derecho al agua, en la sentencia de 1 de febrero de 2006, se hace referencia al acceso al agua potable como condición necesaria para la concreción del derecho a la integridad personal. A partir de las pruebas producidas, la Corte entendió que durante el período de detención en el Centro Penitenciario de Tela y en la Penitenciaría Nacional de Támara, en la ciudad de Puerto Cortés, la presunta víctima fue sometida a condiciones penitenciarias insalubres y de hacinamiento, destacando que no había agua potable, teniendo la víctima que esperar que lloviese para bañarse, careciendo de condiciones higiénicas adecuadas ${ }^{53}$.

La Corte observa que la presunta víctima no fue tratada con el debido respeto a su dignidad humana, y que el Estado incumplió los deberes que le corresponden en su condición de garante de los derechos de los detenidos, razón por la cual la Corte concluye que el Estado es responsable por la violación del derecho a la integridad personal, consagrado en los artículos 5.1, 5.2 y 5.4 de la Convención Americana, en relación con el artículo 1.1 de este instrumento, en detrimento del señor Alfredo López Álvarez ${ }^{54}$. De esta manera, se percibe que el acceso al agua es visto como una condición para la realización del derecho a la integridad personal. Es decir, no es considerado un derecho humano autónomo, lo que será también visto en una decisión de 2009.

En efecto, el 8 de octubre de 2009, la Comisión Interamericana de Derechos Humanos presentó una demanda en contra de la República de Panamá. Este caso

53 Corte Interamericana de Derechos Humanos (2006).

54 Corte Interamericana de Derechos Humanos (2006). 
se refiere a la situación del señor Jesús Tranquilino Vélez Loor, de nacionalidad ecuatoriana, que había sido retenido el 11 de noviembre de 2002 en el Puesto Policial de Tupiza, en la Provincia del Darién, República de Panamá, por no portar la documentación necesaria para permanecer en el país y, posteriormente, había sido trasladado a la Cárcel Pública de La Palma, donde fue mantenido en condiciones inhumanas hasta su deportación a la República del Ecuador, el 10 septiembre de 2003. En lo concerniente al derecho al agua, durante el tiempo que el señor Vélez Loor estaba detenido en la Cárcel Pública de La Palma y en el Centro Penitenciario La Joyita, el Estado reconoció que existían entre otros, el problema en el suministro regular de agua. Como se desprende de la sentencia en cuestión, la Corte estimó probado que en junio de 2003, mientras el señor Vélez Loor se encontraba recluido en el Centro Penitenciario La Joyita, se produjo un problema en el suministro de agua que habría afectado a la población carcelaria.

Los hechos fueron constatados, sobre todo, a partir de una inspección que realizó el personal del Programa de Supervisión de los Derechos de las Personas Privadas de Libertad de la Defensoría del Pueblo de Panamá el 23 de junio de 2003. Un grupo de internos del Centro Penitenciario La Joyita denunció la falta de suministro de agua potable por un período de 15 días en las instalaciones de dicho centro, lo cual habría ocasionado cuadros de deshidratación, diarrea y conjuntivitis en internos de algunos pabellones, así como el desbordamiento de aguas servidas. El 1 de julio de 2003 el personal de la Defensoría realizó nuevamente una visita, constatando que el Centro Penitenciario aún permanecía sin agua debido a un problema eléctrico que había afectado el suministro ${ }^{55}$.

Según la Corte, la prueba alegada demuestra que las deficiencias en el suministro de agua potable en el Centro Penitenciario La Joyita han sido una constante y que en el año 2008 el Estado habría adoptado algunas medidas al respecto. Se observa además que la falta de suministro de agua para el consumo humano es un aspecto particularmente importante de las condiciones de detención.

Por otro lado, se destaca que el Comité de Derechos Económicos, Sociales y Culturales de las Naciones Unidas ha señalado que los Estados Partes deben adoptar medidas para velar para que "los presos y detenidos tengan agua suficiente y salubre para atender a sus necesidades individuales cotidianas, teniendo en cuenta las prescripciones del derecho internacional humanitario y las Reglas mínimas para el tratamiento de los reclusos". En consecuencia, los Estados deben adoptar

55 Corte Interamericana de Derechos Humanos (2010). 
medidas para garantizar que las personas privadas de libertad tengan acceso a agua suficiente y salubre para atender sus necesidades individuales cotidianas, entre ellas, el consumo de agua potable cuando lo requiera, así como para su higiene personal ${ }^{56}$. Sin embargo, como analiza Chávarro ${ }^{57}$, la Corte no determina lo que debe ser entendido como suficiente, es decir, no apunta cuál es la cantidad de agua potable mínima que debe ser garantizada a los individuos privados de su libertad para que, de hecho, puedan satisfacer sus necesidades diarias básicas.

El Tribunal considera que la ausencia de las condiciones mínimas que garanticen el suministro de agua potable dentro de un centro penitenciario constituye una falta grave del Estado a sus deberes de garantía hacia las personas que se encuentran bajo su custodia, toda vez que las circunstancias propias del encierro impiden que las personas privadas de libertad satisfagan por cuenta propia una serie de necesidades básicas que son esenciales para el desarrollo de una vida digna tales como el acceso a agua suficiente y salubre ${ }^{58}$.

De este modo, la Corte estableció que las condiciones de detención en la Cárcel Publica de La Palma y en el Centro Penitenciario La Joyita, en su conjunto, constituyeron tratos crueles, inhumanos y degradantes contrarios a la dignidad del ser humano en violación del artículo 5.1 y 5.2 de la Convención, en relación con el artículo 1.1 de dicho instrumento, en perjuicio del señor Vélez Loor.

Como se percibe en los juzgados arriba, la Corte afirma que el acceso al agua es condición necesaria para la concreción del trato humano digno del individuo que está bajo custodia y para la protección de la integridad personal. De este modo, se observa que la Corte Interamericana de Derechos Humanos reconoce la importancia del acceso al agua, pero retrocede al no afirmarlo como un derecho humano autónomo, y sí sólo como condición para el ejercicio de otros derechos. Se pone el derecho al agua como un derecho secundario, derivado de otros derechos, lo que debilita la protección de tal derecho. Como afirma Jolly59, "enfatizar el derecho humano de acceso al agua potable hace más que subrayar su importancia. Fundamenta la prioridad que deben tener los derechos sociales y económicos, enfatizando las obligaciones de los Estados Partes de asegurar el acceso e identificando la obligación de los Estados Partes de prestar apoyo inter-

56 Corte Interamericana de Derechos Humanos (2010).

57 Chávarro (2014), p. 50.

58 Corte Interamericana de Derechos Humanos (2010).

59 GLEICK (2007), p. 3. 
nacionalmente y nacionalmente". Otras decisiones que también hacen alusión al acceso al agua se refieren a los derechos de los pueblos indígenas. Sin embargo, también en estos casos se percibe la visión del derecho al agua como un derecho inferido de otros derechos.

\subsection{Los casos relativos a los pueblos indígenas: el acceso al agua como derecho secundario}

Otros fallos que hacen referencia expresa al acceso al agua son los relativos a los pueblos indígenas. Por ejemplo, el 17 de marzo de 2003, la Comisión Interamericana de Derechos Humanos sometió a la Corte Interamericana una demanda contra el Estado del Paraguay, bajo la alegación de que el referido Estado no garantizó el derecho de propiedad ancestral de la Comunidad indígena Yakye Axa y de sus miembros. De hecho, desde 1993 se encontraba en tramitación la solicitud de reivindicación territorial de la citada Comunidad, sin que se resolviese satisfactoriamente, lo que implicó la imposibilidad de la Comunidad y de sus miembros de tener acceso a la propiedad y a la posesión de su territorio, causando vulnerabilidad alimentaria, médica y sanitaria a sus miembros. Para Guerra ${ }^{60}$, "se trata, principalmente, de un precedente en el que queda ostensiblemente expuesto el ejercicio que el juez desarrolla ponderando la relación entre derechos a objeto de ser lo más garantista y congruente con el corpus juris de derechos humanos".

En ese sentido, en la sentencia de 17 de junio de 2005, es posible extraer una referencia expresa al derecho al agua a partir de la interpretación que la Corte realiza en relación con los derechos a la vida y a la salud. En lo que se refiere al derecho a la vida, la Corte señala que, esencialmente, éste "comprende no sólo el derecho de todo ser humano de no ser privado de la vida arbitrariamente, sino también el derecho de que no se creen condiciones que le impidan o dificulten el acceso a una existencia digna61".

De este modo, el Estado tiene el deber de adoptar medidas positivas, concretas y orientadas a la satisfacción del derecho a una vida digna, especialmente cuando se trata de personas en situación de vulnerabilidad y riesgo, a semejanza de las comunidades indígenas, como se presenta en el caso. Este deber deriva de todo el corpus juris internacional existente sobre la protección especial de estas comunida-

60 Mitre (2012), p. 244.

61 Corte Interamericana de Derechos Humanos (2005). 
des. Es decir, el deber general de garantía contenido en el artículo 1.1, el deber de desarrollo progresivo contenido en el artículo 26, los artículos 10 (Derecho a la salud); artículo 11 (Derecho a un Medio Ambiente Sano); artículo 12 (Derecho a la alimentación); artículo 13 (Derecho a la Educación) y artículo 14 (Derecho a los Beneficios de la Cultura) del Protocolo Adicional a la Convención Americana en materia de Derechos Económicos, Sociales y Culturales, y a las disposiciones pertinentes del Convenio 169 de la OIT ${ }^{62}$.

En ese contexto, entendió la Corte que los miembros de la Comunidad Yakye Axa viven en condiciones de extrema miseria como consecuencia de la falta de tierra y de acceso a recursos naturales, así como de la precariedad del asentamiento temporal en el que se vieron obligados a permanecer a la espera de la resolución de su solicitud de reivindicación de las tierras, en el cual quedaron imposibilitados de tener acceso a una vivienda adecuada, así como al agua limpia y a servicios sanitarios.

Con base en la Observación General No 14, sobre el derecho de disfrutar del más alto nivel posible de salud del Comité de Derechos Económicos, Sociales y Culturales de las Naciones Unidas, la Corte resalta que "las afectaciones especiales en el derecho a la salud, e íntimamente vinculadas con éste en el derecho a la alimentación y en el acceso al agua limpia afectan de manera aguda el derecho a una existencia digna y las condiciones básicas para el ejercicio de otros derechos humanos, como el derecho a la educación o el derecho a la identidad cultural".

De este modo, en el caso de los pueblos indígenas, el acceso a sus tierras ancestrales y al uso y disfrute de los recursos naturales que en ellas se encuentran están directamente vinculados con la obtención de alimento y el acceso al agua limpia. A este respecto, el citado Comité de Derechos Económicos, Sociales y Culturales destacó la especial vulnerabilidad de muchos grupos de pueblos indígenas cuyo acceso a las tierras ancestrales puede verse amenazado y, en ese sentido, su posibilidad de tener acceso a medios para obtener alimento y agua limpia ${ }^{63}$.

La Corte estableció que el Estado no había garantizado el derecho de los miembros de la Comunidad Yakye Axa a la propiedad comunitaria, lo que afectó el derecho a una vida digna de los miembros de la Comunidad, ya que les privó de la posibilidad de acceder a los medios de subsistencia tradicionales, así como al uso y disfrute de los recursos naturales necesarios para la obtención de agua

62 Corte Interamericana de Derechos Humanos (2005).

63 Corte Interamericana de Derechos Humanos (2005). 
limpia y para la práctica de la medicina tradicional de prevención y cura de enfermedades. Además, el Estado no adoptó las medidas positivas necesarias que permitieran asegurar a los miembros de la Comunidad Yakye Axa las condiciones de vida compatibles con su dignidad durante el período en que permanecieron sin territorio. De esta manera, se percibe que, una vez más, el derecho al agua es inferido de otros derechos y no garantizado de manera autónoma. Otra decisión en el mismo sentido, es el caso Comunidad Indígena Sawhoyamaxa vs. Paraguay. El 3 de febrero de 2005 la Comisión Interamericana de Derechos Humanos sometió ante la Corte Interamericana una demanda contra el Estado del Paraguay, afirmando que el Estado no ha garantizado el derecho de propiedad ancestral de la Comunidad Sawhoyamaxa y sus miembros, ya que desde 1991 se encontraba en tramitación su solicitud de reivindicación territorial, sin que se la hubiese resuelto satisfactoriamente. Lo que implicaba la imposibilidad de la Comunidad y la de sus miembros de acceder a la propiedad y posesión de sus tierras, llevándoles a vivir en un estado de vulnerabilidad alimenticia, médica y sanitaria.

En la sentencia de 29 de marzo de 2006, en la que se encuentra relatada toda la situación de miseria de dicha comunidad, se observa, a partir de prueba pericial, que "se realizó un recorrido por la aldea, lo cual permitió detectar que sus habitantes no cuentan con fuente de agua potable. La fuente de mayor fiabilidad puede ser el agua de lluvia recogida, pero por falta de almacenamiento ésta es muy reducida. Así, los tajamares que se encuentran dentro de las tierras alambradas que son reclamadas por la Comunidad indígena Sawhoyamaxa como suyas son la principal fuente de agua, por lo que sus miembros tienen que entrar furtivamente para obtener agua para su aseo personal y para uso propio. El agua está expuesta al contacto con animales salvajes y animales criados en la estancia, y recibe los desechos que la lluvia arrastra ${ }^{64 "}$.

Para analizar la situación en cuestión, la Corte expone su interpretación acerca del derecho a la vida y del derecho a la integridad personal, estableciendo, por lo tanto, relación con el derecho al agua. En cuanto al derecho a la vida, resalta que de conformidad con el artículo 27.2 de la Convención este derecho forma parte del núcleo inderogable, razón por la cual los Estados tienen la obligación de garantizar la creación de las condiciones que se requieran para que no se produzcan violaciones de ese derecho inalienable. Así, "ha señalado en su jurisprudencia constante que el cumplimiento de las obligaciones impuestas por el artículo $4^{\circ} \mathrm{de}$

${ }^{64}$ Corte Interamericana de Derechos Humanos (2006). 
la Convención Americana, relacionado con el artículo 1.1 de la misma, no sólo presupone que ninguna persona sea privada de su vida arbitrariamente (obligación negativa), sino que además, a la luz de su obligación de garantizar el pleno y libre ejercicio de los derechos humanos, requiere que los Estados adopten todas las medidas apropiadas para proteger y preservar el derecho a la vida (obligación positiva) de todos quienes se encuentren bajo su jurisdicción ${ }^{65}$ ".

En relación con el caso en cuestión, la Corte reconoce que, junto con la carencia de tierra, la vida de los miembros de la Comunidad Sawhoyamaxa se caracteriza por el desempleo, el analfabetismo, las tasas de morbilidad por enfermedades evitables, la desnutrición, las precarias condiciones de su vivienda y entorno, las limitaciones de acceso y uso de los servicios de salud y agua potable, así como la marginalización por causas económicas, geográficas y culturales. Esta situación, por lo tanto, imposibilita el ejercicio de una vida digna.

De este modo, la Corte declaró que el Estado violó el artículo 4.1 de la Convención Americana, en relación con el artículo 1.1 de la misma, por cuanto no ha adoptado las medidas positivas necesarias dentro del ámbito de sus atribuciones, que razonablemente eran de esperarse para prevenir o evitar el riesgo al derecho a la vida de los miembros de la Comunidad Sawhoyamaxa. ${ }^{66}$ En la misma dirección, el caso Comunidad Indígena Xákmok Kásek vs. Paraguay.

Efectivamente, el 3 de julio de 2009 la Comisión Interamericana de Derechos Humanos sometió ante la Corte Interamericana una demanda contra el Estado del Paraguay, de conformidad con los artículos 51 y 61 de la Convención, bajo la alegación de que no se garantizaba el derecho de propiedad ancestral de la Comunidad Indígena Xákmok Kásek y de sus miembros, ya que desde 1990 se encontraba tramitando la solicitud de reivindicación territorial de la Comunidad sin solución satisfactoria, lo que no sólo significaba la imposibilidad de que la Comunidad tuviese acceso a la propiedad y la posesión de su territorio, sino también un estado de vulnerabilidad alimentaria, médica y sanitaria, que amenazan de forma continua la supervivencia de sus miembros.

De acuerdo con la sentencia de 24 de agosto de 2010, se constató el estado de especial vulnerabilidad en el que se encontraban los miembros de la Comunidad, al no tener la titularidad de sus tierras, lo que violaba el derecho a la vida, derecho

65 Corte Interamericana de Derechos Humanos (2006).

66 Corte Interamericana de Derechos Humanos (2006). 
humano fundamental, cuyo goce pleno es un requisito previo para el disfrute de todos los demás derechos humanos.

Partiendo de la comprensión del derecho a la vida digna, la Corte hace referencia expresa al acceso y a la calidad del agua. Sostiene que, sobre la base de las pruebas producidas, desde el año 2003 los miembros de la Comunidad no tenían servicio de distribución de agua y que "a partir de abril de 2009, en virtud del Decreto No 1.830, el Estado suministró agua a los miembros de la Comunidad, lo que se asentó en las siguientes cantidades: 10.000 litros el 23 de abril de 2009, 20.000 litros el 3 de julio de 2009, 14.000 litros el 14 de agosto de 2009, y 20.000 litros el 10 de agosto de 2009. El 5 de febrero de 2010, el Estado indicó que había entregado cinco depósitos de agua de $6000 \mathrm{~m}^{3}$ a la Comunidad ${ }^{67}$.

Además, la Corte apunta que el agua suministrada por el Estado durante los meses de mayo a agosto de 2009 no supera 2,17 litros por persona al día, cantidad muy reducida si se compara con el mínimo de 7,5 litros por día para satisfacer el conjunto de las necesidades básicas, que es indicado, según la Corte, por los estándares internacionales. Añade, además, que el agua debe ser de una calidad que represente un nivel tolerable de riesgo, lo que, basándose en las normas indicadas, no ha sido demostrado por el Estado. El Estado no envió prueba actualizada sobre el suministro de agua durante el año 2010, ni tampoco demostró que los miembros de la Comunidad tenían acceso a fuentes seguras de agua.

Sobre este punto, Chávarro ${ }^{68}$ sostiene que la Corte interpretó equivocadamente las normas relativas a la cantidad mínima de agua que debe garantizarse a todo individuo, teniendo en cuenta que todos los estándares internacionales indican que la cantidad mínima debe ser al menos de 20 litros por día, resaltando así la necesidad de la Corte de rectificar esta información para impedir que los Estados utilicen la referencia de 7,5 litros como importe mínimo para realizar este derecho. Por consiguiente, la Corte considera que las gestiones que el Estado ha realizado no han sido suficientes para proveer a los miembros de la Comunidad de agua en cantidad suficiente y calidad adecuada, lo que los expone a riesgos y enfermedades ${ }^{69}$.

67 Corte Interamericana de Derechos Humanos (2010).

68 Cháarro (2014), p. 62.

69 Corte Interamericana de Derechos Humanos (2010). 
En este aspecto, Parriciatu ${ }^{70}$ refuerza que si las comunidades indígenas permanecen sin sus tierras, los Estados tienen la obligación de suministrar servicios básicos y bienes necesarios para su subsistencia, por ejemplo, de agua potable, según determinan las disposiciones generales internacionales. En consecuencia, la Corte declara que el Estado no ofreció las prestaciones básicas para proteger el derecho a una vida digna en estas condiciones de riesgo especial, real e inmediato para esta comunidad, lo que constituye una violación del artículo 4.1 de la Convención, en relación con el artículo 1.1.

Aunque el enfoque de este trabajo sea la función contenciosa de la Corte, se pueden también mencionar dos casos ante la Comisión Interamericana que protegen el derecho al agua al proteger el derecho de propiedad. Es el caso de la Central Hidroeléctrica Ralco ${ }^{71}$, en el cual los denunciantes eran miembros del pueblo Mapuche Pehuenche, del sector Alto del Bío Bío, VIII Región de Chile. Efectivamente, en octubre de 1993 se aprobó un proyecto de la empresa Endesa, para construir una central hidroeléctrica en Ralco, zona en la cual vivían los denunciantes. Muchos territorios fueron inundados y los miembros Mapuche Pehuenche tuvieron que ser relocalizados. En consecuencia de la denuncia, fue firmada una solución amistosa entre los miembros de las familias desplazadas y el Estado del Chile en 2004, garantizando el derecho de propiedad de la comunidad. Aunque tal solución haya sido un logro para las familias y su derecho al territorio, incluso a los recursos hídricos, el no respeto de tal acuerdo representa, aún en 2017, un obstáculo para la efectividad de los derechos indígenas, sobre todo del derecho de propiedad y, por consiguiente, del acceso al agua. Es así necesario trabajar para que los derechos de estas comunidades sean realizados efectivamente, monitoreando a los Estados para que cumplan con las decisiones emitidas en el ámbito interamericano.

Otro caso similar, que aún sigue sin solución, es el caso del Agua Mineral Chuzmiza $^{72}$, en el cual las comunidades indígenas Aymara y Atacama de Chusmiza y Usmagama alegaron que el Estado había privado a la Comunidad de la posesión material y del derecho de propiedad ancestral sobre las aguas de la vertiente denominada Socavón de Chusmiza. En este caso se percibe que el derecho de aguas y el derecho humano al agua son interdependientes. Posteriormente, la comunidad

\footnotetext{
70 Parriciatu y Sindico (2012), p. 233.

71 Comisión Interamericana de Derechos Humanos (2004).

72 Comisión Interamericana de Derechos Humanos (2013).
} 
alegó la falta de ejecución de la sentencia de la Corte Suprema de Justicia de 2009 que reconoció tal derecho a la Comunidad y el retardo injustificado en resolver las demandas de indemnización. De acuerdo con el informe de la Comisión, las aguas eran de extrema importancia para los peticionarios, ya que habrían sido utilizadas desde tiempos inmemoriales por la Comunidad para el desarrollo de sus actividades productivas agrícolas y para el consumo humano, siendo el único recurso hídrico disponible en la zona. La Comisión consideró la petición admisible y viene trabajando para que el Estado de Chile y la comunidad lleguen a una solución amistosa. En octubre de 2017 el Comisionado Luis Vargas, Relator de la CIDH para Chile, facilitó una reunión de trabajo en este caso y valoró la disposición de las partes para avanzar en los procesos de negociación de una solución amistosa ${ }^{73}$.

De esta forma, como se ha dicho anteriormente, en términos de judicialidad, los mecanismos desarrollados en la última década por la Corte y la Comisión han reconocido derechos especiales a los pueblos indígenas, a modo de ejemplo del acceso al agua, aunque derivado de otros derechos, con un foro judicial efectivo para su realización ${ }^{74}$.

Sin embargo, tanto en el caso de los derechos de los detenidos como en el caso de los pueblos indígenas, el derecho al agua es considerado como un derecho derivado de otros derechos. En efecto, en el caso de los detenidos, el derecho al agua es condición para la realización del respeto a la dignidad, a la integridad personal y a la prohibición de tratos crueles, inhumanos y degradantes. Por otro lado, en el caso de los pueblos indígenas, el derecho al agua es visto como condición para disfrutar del más alto nivel posible de salud, para el respeto del derecho a la vida y del derecho a la integridad personal, y, sobre todo, es parte del derecho de propiedad, que incluye los recursos hídricos necesarios para la sobrevivencia de estas comunidades. Se percibe así, que en ningún momento se habla de derecho humano al agua de forma autónoma, lo que corresponde a una limitación de la protección de este derecho en el Sistema Interamericano. El derecho humano al agua debería ser reconocido, y así ser visto como un límite a la asignación de los recursos hídricos.

Se puede verificar que, como para todos los derechos económicos, sociales y culturales, hay una dificultad en el reconocimiento del derecho humano al agua y su consideración como un derecho autónomo, como son los derechos civiles y

73 Comisión Interamericana de Derechos Humanos (2017).

74 Parriciatu y Sindico (2012), p. 234. 
políticos. Como afirma Movilla ${ }^{75}$, "los Estados son cautelosos a la hora de secundar avances en el ámbito de los derechos económicos, sociales y culturales". De hecho, algunos consideran los derechos económicos y sociales como derechos inferiores a los derechos civiles y políticos. Como explica Pisarello ${ }^{76}$, una de estas críticas afirma que los derechos civiles y políticos, a diferencia de los derechos sociales, estarían relacionados más estrechamente a bienes que son fundamentales para cualquier persona, como su vida, su integridad física, su libertad de expresión, y así, a su dignidad. Todavía, es imposible disfrutar de los derechos civiles personalísimos si no tenemos acceso a los derechos sociales básicos, a la alimentación, al agua, a la vivienda, a la salud.

Otro argumento que se atribuye a los derechos sociales, distinguiéndolos de los derechos civiles y políticos, es el que afirma que los derechos sociales no son derechos exigibles por no presentar contenidos específicos y son derechos caros. No obstante, como se ha visto en la primera parte de este trabajo, el contenido del derecho al agua está claro y definido específicamente en el ámbito internacional. Además, tanto los derechos sociales como los derechos civiles y políticos requieren la mediación del legislador e inversión de recursos para realizarlos, ambos prescriben obligaciones negativas así como positivas.

Todos los derechos humanos deberían ser vistos como una unidad, como afirma la Declaración y el Programa de Acción de Viena, que dejó establecido el carácter universal, indivisible, interdependiente e interrelacionado de los derechos humanos y comprometió a los Estados a promover y proteger todos los derechos humanos de todas las personas de manera igual ${ }^{77}$.

\section{CONCLUSIONES}

El derecho humano al agua ha sido reconocido formalmente en el marco del Derecho Internacional de los Derechos Humanos, sobre todo en el sistema de las Naciones Unidas. El contenido de este derecho ha sido definido expresamente en la Observación General No 15 del Comité de Derechos Económicos, Sociales y Culturales. Tal hecho es crucial, ya que muchos aún sufren con la ausencia de agua. El reconocimiento de este derecho y la definición de su contenido subraya su

75 Movilla (2012), p. 27.

76 Pisarello (2007), p. 37.

77 NaCiones Unidas (1993). 
importancia y las obligaciones de los Estados para ponerlo en práctica. A pesar de ello, en el ámbito interamericano, tal derecho aún no ha sido reconocido por los instrumentos normativos que integran este Sistema. Sin embargo, ante el análisis jurisprudencial realizado, se constató que la Corte Interamericana de Derechos Humanos reconoce el acceso al agua como un derecho derivado de otros derechos expresamente tutelados, sobre todo del derecho a la vida.

La Corte comprende que el derecho a la vida corresponde no sólo al derecho de todo ser humano de no ser privado de ella arbitrariamente, sino también el derecho de que no se creen condiciones que le impidan o dificulten el acceso a una existencia digna, lo que impone al Estado la obligación de adoptar medidas positivas, concretas y orientadas a la satisfacción del derecho a una vida digna, lo cual exige, a su vez, el acceso al agua potable de calidad para consumo e higiene.

Así, la Corte, al comprender en los referidos juzgados que el acceso al agua es conditio sine qua non para el goce de una gama de derechos humanos, ha protegido y reconocido este derecho a través de otros ya dispuestos por la Convención Americana de los Derechos Humanos, como su artículo $4^{\circ}$. Sin embargo, a la luz de la jurisprudencia examinada, la Corte Interamericana de Derechos Humanos retrocede al no reconocer el derecho humano al agua como un derecho autónomo, y lo hace sólo como condición para el ejercicio de otros derechos. Aunque, en términos de protección, avanza al reconocer la responsabilidad del Estado en razón de su violación.

\section{Bibliografía CitAdA}

AL JAYYOUSI, Odeh Rashed (2007): "Water as a Human Right: Towards Civil Society Globalization", en International Journal of Water Resources Development, Volumen 23 (No 2), pp. 329-339.

Belaidi, Nadia y EuZEN, Agathe (2009): "De la chose commune au patrimoine commun", en Mondes en développement (No 145), pp. 55-72.

Buob Concha, Luis Carlos (2012): "Criterios y Mecanismos para la Protección Jurídica del Derecho Humano al Agua de los Pueblos Indígenas en su Dimensión Colectiva a través de la Corte Interamericana de Derechos Humanos", tesis de grado (Universidad Peruana de Ciencias Aplicadas).

CAHILl, Amanda (2005): "The human right to water - a right of unique status: The legal status and normative content of the right to water", en The International Journal of Human Rights, Volumen 9 (No 3), pp. 389-410. 
Caney, Simon (2010): "Climate Changes, Human Rights and moral thresholds", en Human Right and Climate Change (Cambridge, Cambridge University Press), pp. 69-90.

ChÁvarro, Jimena (2014): "The Right to Water in the Case-Law of the InterAmerican Court of Human Rights", en ACDI, pp. 39-68.

Comité de Derechos Humanos (1982): "Observación General No 6. El derecho a la vida (art. 6 PIDCP)”, doc. HRI/GEN/1/Rev. 0, Volumen. I.

Comité de Derechos Económicos, Sociales y Culturales (2002): Observación General No 15 El derecho al agua (artículos 11 y 12 del Pacto Internacional de Derechos Económicos, Sociales y Culturales).

Comisión Interamericana de Derechos Humanos (2015): "Informe sobre el acceso al agua en las Américas: una aproximación al derecho humano al agua en el sistema interamericano". [Fecha de consulta: 25 de enero de 2018]. [Disponible en: http://www.oas.org/es/cidh/docs/anual/2015/doc-es/ InformeAnual2015-cap4A-agua-ES.pdf].

Comisión Interamericana de Derechos Humanos (2017): Report on the 165 Regular Period of Sessions of the IACHR, Annex to Press Release, 168-17.

De Albuquerque, Catarina (2012): Derechos hacia el final. Buenas prácticas en la realización de los derechos al agua y al saneamiento, (Lisboa: Ongawa).

De CARLI, Ana Alice (2013): A água e seus intrumentos de efetividade, (São Paulo, Millenium Editora).

De Luis Romero, Elena; Fernández Aller, Carles y Guzmán Acha, Cristina (2013): "Derecho humano al agua y al saneamiento: derechos estrechamente vinculados al derecho a la vida", Tribuna abierta, pp. 217-236.

De Oliveira Mazzuoli, Valerio (2015): Curso de Direito Internacional Público (São Paulo, Revista dos Tribunais).

El HadjI, Guisse (2005): La realización del derecho al agua potable y al saneamiento, doc. E/CN.4/Sub.2/2005/25. [Fecha de consulta: 23 de enero de 2018]. [Disponible en: http://www.adelco.org/wp-content/uploads/2015/11/ Agua_Derecho_Humano.pdf].

FARIAS, Thiago Daniel (2013): "A Comissão Interamericana de Direitos Humanos como um órgão permeador de direitos", en $A$ Corte Interamericana de Direitos Humanos e sua jurisprudencia" (São Paulo, Boreal), pp. 3-18.

GARCíA, Aniza (2008): El derecho humano al agua (Madrid, Editorial Trotta).

Gleick, Peter H. (2007): The Human Right to Water, (Oakland, Pacific Institute). 
Mitre Guerra, Eduardo (2012): “La protección del derecho al agua en el derecho constitucional comparado y su introducción en los criterios de tribunales internacionales de derechos humanos", en Pensamiento Jurídico (No 35), pp. 231-252.

Mitre Guerra, Eduardo José (2012): El derecho al agua - naturaleza jurídica y protección legal en los ámbitos nacionales e internacional, (Madrid: Iustel).

Hartemann, Philippe (2013): "Eau de consommation, risque, santé", en Sciences Eaux \& Territoires (No 10), pp. 14-21.

Hennebel, Ludovic y Tigroudja, Hélène (2009): Le particularisme interaméricain des droits de l'homme (Paris, Editions A. Pedone).

Howard, Guy y Bartram, Jamie (2003) : Domestic water quantity, service level and health, (Geneva, World Health Organization).

Human Rights Council (2010): Resolution 15/9, Human Rights and access to safe drinking water and sanitation. [Fecha de consulta: 24 de enero de 2018]. [Disponible en: http ://www.right2water.eu/sites/water/files/UNHRC\%20 Resolution\%2015-9.pdf].

LEB, Christina (2012): "The right to water in a transboundary context: emergence of seminal trends", en Water International, pp. 640-653.

Martinetti, Françoise (2007): Les droits de l'enfant (Paris, E.J.L.).

McGraw, George (2010): "Water for Life: The Challenge Posed by the Uncodified Human Right to Water in International Law", en The University for Peace Law Review, pp. 39-51.

MicKelson, Karin (2000): "South, North, International Environmental Law, and International Environmental Lawyers", en Yearbook of International Environmental Law (Volumen 11), pp. 52-81.

Movilla Pateiro, Laura (2012): "Hacia la realización del derecho humano al agua y al saneamiento: el papel de la Relatora Especial", Revista Electrónica de Estudios Internacionales, pp. 1-29.

Movilla Pateiro, Laura (2014): El Derecho Internacional del agua. Los acuiferos transfronterizos, (Barcelona, Editorial J. Bosch).

Naciones Unidas, Oficina del Alto Comisionado para los Derechos Humanos, Programa de las Naciones Unidas para los Asentamientos Humanos y Organización Mundial de la Salud (2010): El derecho al agua: folleto informativo No 35. 
Oef, Mandato de la Comisión Interamericana de Derechos Humanos. [Fecha de consulta: 23 de enero de 2018]. [Disponible en: http://www.oas.org/pt/ cidh/mandato/que.asp].

OMs (2008): Guias para la calidad del agua potable (Ginebra, OMS).

Parriciatu, Marco y Sindico, Franceso (2012): "Contours of an Indigenous Peoples' Right to Water in Latin America under International Law", en International Human Rights Law Review (No 1), pp. 211-236.

PISARELlo, Gerardo (2007): Los derechos sociales y sus garantías, (Madrid, Editorial Trotta).

Ramos, André (2002): Processo internacional de direitos humanos (Rio de Janeiro, Renovar).

SalmÓN G., Elizabeth (2012): "El derecho humano al agua y los aportes del sistema interamericano de derechos humanos", en Universitas Revista de Filosofía, Derecho y Politica (No 16), pp. 245-268.

SÁncheZ, Víctor M. (2008): "Hacia un derecho humano fundamental al agua en el derecho internacional", en Revista electrónica de estudios internacionales, pp. 1-23.

SAURA, Jaume (2012): "El derecho humano al agua y al saneamiento en perspectiva jurídica internacional”, en Derechos y libertades (No 26), pp. 145-180.

Scanlon, John: Cassar, Angela y Nemes, Noémi (2004): "Water as a human right ?", en Prefacio de Achin Steiner, IUCN Environmental Policy and Law Paper, (No 51).

Serrano Tur, Lidia (2014): Aguas dulces y derecho internacional: el agua como bien comun y como derecho humano desde la perspectiva del desarrollo sostenible (Barcelona, Huygens Editorial).

SINGH, Nandita (2013): "Translating human right to water and sanitation into reality: a practical framework for analysis", en Water Policy, pp. 943-960.

Steichen, Pascale (2012): Le droit à l'eau dans la jurisprudence de la Cour Européenne des Droits de l'Homme, en Smets, Henri (2012): Le droit à l'eau potable et à l'assainissement en Europe, (Paris, Editions Johanet), pp. 93-103.

Strakos, Paula (2016): "Água como direito humano: estudo comparado de sua proteção nas esferas judiciais interamericana e europeia", en Revista da Faculdade de Direito - UFPR (Volumen 61, No 3), pp. 141-164.

TAYLOR, Rachel and NyLUnd, Katharine (2013): "Tapped out - Threats to the Human Right to Water in the Urban United States", Georgetown Law. 
Tsanga Tabi, Marie y Gremmel, Jeanne (2013): "La difficile émergence du droit à l'eau, de sa reconnaissance internationale à sa mise en oeuvre à l'échelle nationale: les cas de la France et du Royaume-Uni”, en Sciences Eaux \& Territoires (No 10), pp. 56-64.

WINKLER, Inka (2012): The Human Right to Water: Significance, Legal Status and Implications for Water Allocation (Oxford, Hart Publishing).

Who and Unicef (2000): Global Water Supply and Sanitation Assessment 2000 Report, (Geneva/New York,WHO/UNICEF).

Who and Unicef (2015): "Progress on Sanitation and Drinking Water - 2015 update and MDG assessment" (WHO Library). [Fecha de consulta: 23 de enero de 2018]. [Disponible en: http://apps.who.int/iris/bitstre am/10665/177752/1/9789241509145_eng.pdf ].

World Health Organization (2003): "The Right to Water", en Geneva, Health and Human Rights Publication Series, (No 3).

Ziganshina, Dinara (2008): "Rethinking the concept of the human right to water", en Santa Clara Journal of International Law (No 1), pp. 113-128.

\section{NORMAS JURÍDICAS CITADAS}

Carta de la Organización de los Estados Americanos-OEA, 30 de abril de 1948. Carta Africana sobre los Derechos y el Bienestar de los Niños, 11 de julio de 1990. Carta Social de las Américas, 4 de junio de 2012.

Carta Social Europea, 18 de octubre de 1961.

Convención Americana sobre Derechos Humanos, 22 de noviembre de 1969.

Convención Internacional de los derechos del niño, 20 de noviembre de 1989.

Convención sobre los Derechos de las Personas con Discapacidad, 13 de diciembre de 2006.

Convenio sobre la Eliminación de Todas las Formas de Discriminación contra las Mujeres, 18 de diciembre de 1979.

Declaración Americana de Derechos y Deberes del Hombre, 30 de abril de 1948.

Declaración Universal de los Derechos Humanos, 10 de diciembre de 1948.

Declaración y el Programa de Acción de Viena, 25 de junio de 1993.

Pacto Internacional relativo a los Derechos Económicos, Sociales y Culturales, 16 de diciembre de 1966.

Pacto Internacional de Derechos Civiles y Políticos de 1966, 16 de diciembre de 1966. 
Protocolo Adicional a la Convención Americana sobre Derechos Humanos en materia de Derechos Económicos, Sociales y Culturales, 17 de noviembre de 1988.

Resolución de las Naciones Unidas 64/292, 28 de julio de 2010.

Resolución AG/RES. No 2.349 (XXXVII-O/07) "El agua, la salud, y los derechos humanos", de la Asamblea General de la Organización de los Estados Americanos, 5 de junio de 2007.

Resolución AG/RES. No 2.760 (XLII-O/12) "El derecho humano al agua potable y al saneamiento", de la Asamblea General de la Organización de los Estados Americanos, 5 de junio de 2012.

\section{JURISPRUDENCIA CITADA}

Mercedes Julia Huenteao Beroiza y otras con Chile (2004): Comisión Interamericana de Derechos Humanos, Informe No 30/04, Petición 4617/02, Solución Amistosa.

Comunidad Indígena Yakye Axa con Paraguay (2005): Corte Interamericana de Derechos Humanos, 17 de junio de 2005.

López Álvarez con Honduras (2006): Corte Interamericana de Derechos Humanos, 1 de febrero de 2006.

Comunidad Indígena Sawhoyamaxa con Paraguay (2006): Corte Interamericana de Derechos Humanos, 29 de marzo de 2006.

Comunidad Indígena Xákmok Kásek con Paraguay (2010): Corte Interamericana de Derechos, 24 de agosto de 2010.

Vélez Loor con Panamá (2010): Corte Interamericana de Derechos Humanos, 23 de noviembre de 2010.

Comunidad Indígena Aymara de Chusmiza-Usmagama y sus miembros con Chile (2013): Comisión Interamericana de Derechos Humanos, Informe No 29/13, Petición 1288-06, Admisibilidad. 